Article

\title{
Analysis of Cross-Seasonal Spectral Response from Kettle Holes: Application of Remote Sensing Techniques for Chlorophyll Estimation
}

\section{Rahmatulla M. Igamberdiev ${ }^{1, *}$, Ralf Bill $^{2}$, Hendrik Schubert ${ }^{3}$ and Bernd Lennartz ${ }^{2}$}

1 Institute for Geography and Geology, University of Greifswald, Friedrig-Ludwig-Jahn-Str. 16, D-17487 Greifswald, Germany;

2 Faculty for Agricultural and Environmental Sciences, University of Rostock, Justus-von-Liebig-Weg 6, D-18059 Rostock, Germany; E-Mails: ralf.bill@uni-rostock.de (R.B.); bernd.lennartz@uni-rostock.de (B.L.)

3 Institute for Aquatic Ecology, University of Rostock, Albert-Einstein-Straße 3, D-18051 Rostock, Germany; E-Mail: hendrik.schubert@biologie.uni-rostock.de

* Author to whom correspondence should be addressed;

E-Mail: rahmatulla.igamberdiev@uni-greifswald.de; Tel.: +49-3834-86-4500; Fax: +49-3834-86-4501.

Received: 25 September 2012; in revised form: 9 November 2012 / Accepted: 12 November 2012 / Published: 16 November 2012

\begin{abstract}
Kettle holes, small inland water bodies usually less than 1 ha in size, are subjected to pollution, drainage, and structural alteration by intensive land use practices. This study presents the analysis of spectral signatures from kettle holes based on in situ water sampling and reflectance measurements in application for chlorophyll estimation. Water samples and surface reflectance from kettle holes were collected from 6 ponds in 15 field campaigns ( 5 in 2007 and 10 in 2008), resulting in a total of 80 spectral datasets. We assessed the existing semi-empirical algorithms to determine chlorophyll content for different types of kettle holes using seasonal and cross-seasonal volume reflectance and derivative spectra. Based on this analysis and optical properties of water leaving reflectance from kettle holes, the following typology of the remote signal interpretation was proposed: Submerged vegetation, Phytoplankton dominated and Mixed type.
\end{abstract}

Keywords: small shallow waters; spectral signatures; chlorophyll concentration 


\section{Introduction}

The acquisition of inland water quality (WQ) parameters by means of remote sensing is an important but tedious task due to the pronounced spatial and temporal variability of the most in-water constituents, especially in small shallow water bodies. Small inland waters such as kettle holes (usually less than 1 ha in size) are subjected to pollution, drainage, and structural alteration by intensive land use practices [1]. Therefore, the fast yet efficient and precise determination of the water quality and the temporal development in kettle holes is required to assess the sustainability of agricultural and conservation measures, as well as to evaluate the impact of changing weather conditions on terrestrial ecosystems in general [2].

Hyperspectral Remote Sensing (HRS) provides data in contiguous narrow bands which may assist in WQ monitoring campaigns [3]. Over the last two decades, visible and near-infrared spectroscopy (VNIRS) has evolved as an important nondestructive tool to characterize soil, vegetation and water bodies. Compared to conventional laboratory analysis, VNIRS is accepted as rapid and potentially cost-effective method. Additionally, it can be applied in the field by portable spectrometers [4]. Field spectroscopy has an important role in environmental science in which it allows to characterize the object being observed with in situ measurements [5]. With proper equipment and methodology, spectrometry can be conducted under a variety of conditions [6].

Spectral reflectance is widely used for qualitative and quantitative assessments of the in-water constituents including algae chlorophyll content [7-11]. However, the water leaving signal is highly influenced by surface, volume (water column) and bottom of water bodies $[12,13]$. Therefore, the subsurface irradiance reflectance (volume or normalized reflectance) is used in semi-analytical methods to correlate with the water constituent concentrations. Volume reflectance is nearly independent of atmospheric properties and entirely determined by the Inherent Optical Properties (IOPs) and its constituents [14]. At the same time, the quantification of water quality parameters (e.g., chlorophyll content) in shallow waters and their corresponding remotely sensed data can be linear or nonlinear, but are nearly always site specific [15].

Kneubuehler et al. [16] analyzed all existing semi-empirical algorithms for spectrophotometric data collected from shallow lakes with a water depth of app. 1-2 m. The Magnitude of the Peak Above a Baseline and the Position of the Peak algorithms showed promising results when using a linear curve fit with a relative error of $8 \%$ and $6 \%$, respectively [3]. Wiangwang [7] identified optimal spectral bands which are the most sensitive to water quality indicators using volume reflectance over Michigan lakes. Igamberdiev et al. [3] compared the existing semi-empirical algorithms to determine chlorophyll content for several kettle holes with in situ data collected between July and October 2007 at five occasions. Linear regression between TCHL (total chlorophyll) and Peak Magnitude algorithm gave best results for kettle holes with high algae concentration $\left(0.80<R^{2}<0.99\right)$. At low algae contents, however, Peak Magnitude Above a Baseline and Position of Peak algorithms and CHL gave consistent correlations. These results showed that the response of the kettle holes to agricultural activity in terms of water quality can be determined by means of remote sensing. However, no single relationship exists for the various types of kettle holes that relate spectral information to chlorophyll concentration.

Therefore, the objective of this research article is to analyze the cross-seasonal spectral signatures from kettle holes based on two-year field spectrometry data (collected on 2007 and 2008 cropping 
seasons). The specific objective is to show a typology of spectral response using semi-empirical algorithms for biomass estimations and accuracy assessment of these methods.

\section{Methods}

\subsection{Study Area}

The test area is located close to Demmin (small town), about $150 \mathrm{~km}$ north of the city of Berlin, and covers approximately $10 \mathrm{~km}^{2}$ (Figure 1). A survey in May 2007 showed that all kettle holes are within agricultural fields and have different shapes, sizes, depths, water regimes and trophic states. After elimination of permanently dry kettle holes, the primary monitoring program included nine sampling stations (Figure 1). However, some kettle holes dry out during summer, so the kettle holes K8 and K9 were excluded from further monitoring. Kettle hole K3 was entirely covered by duckweed (botanic Lemna spp.) and was also not considered in the study. In the summer of 2008, kettle hole K2 dried out and it was also excluded from further monitoring.

Figure 1. True color composite image (15 May 2008) of test area (close to the village Schmarsow, Demmin suburbs, Germany) with kettle holes numeration.

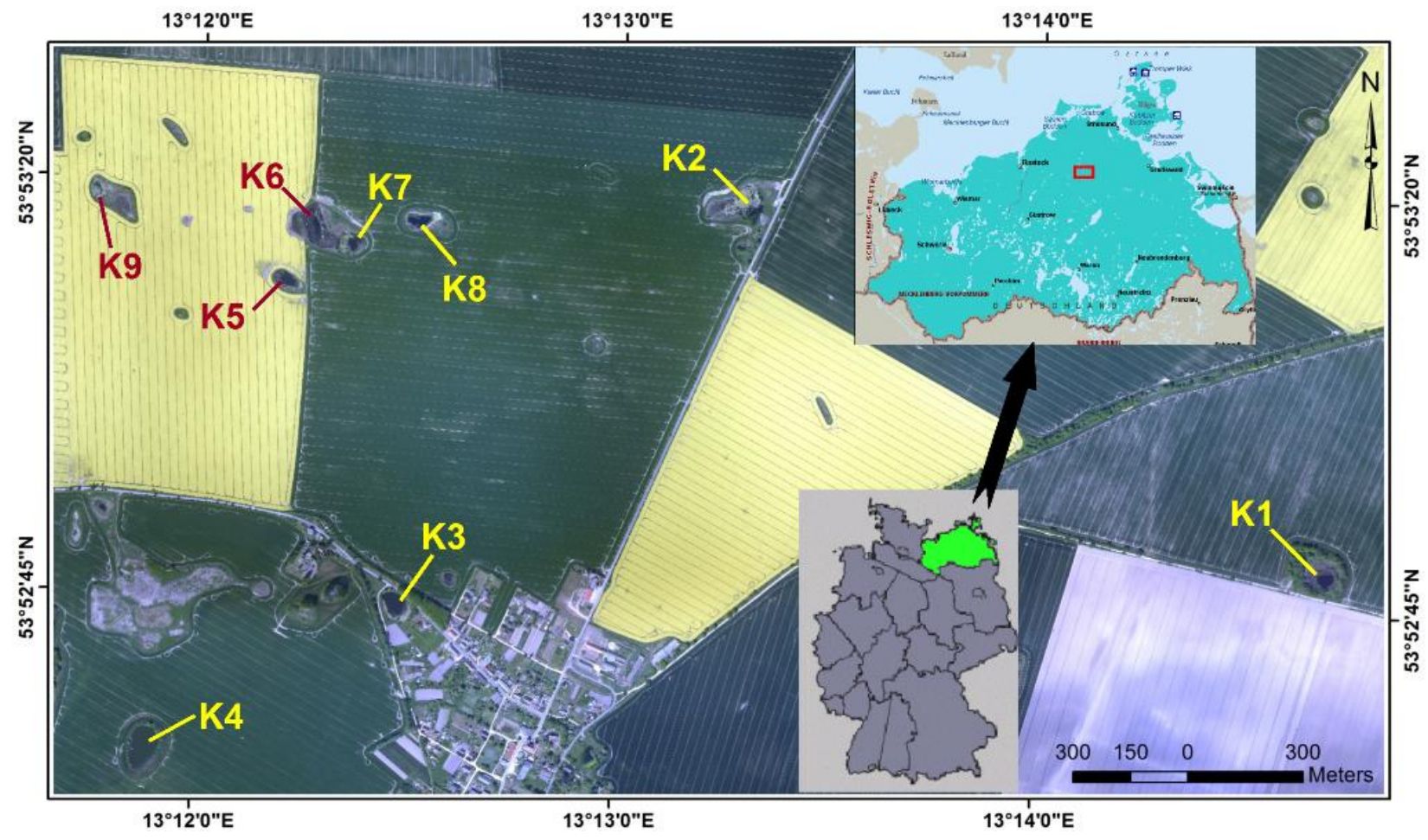

\subsection{Kettle Holes' Hydro-Morphological Characteristics}

The basis for the characterization of the kettle holes was the investigation of hydro-morphological factors (length, width, depth, shore slope and algae content) and the application of the typology as described by Kalettka and Rudat [17]. Field research showed that all kettle holes belong to the "storage type" with semi-permanent and permanent water regimes. Subtype categories, according to Kalettka and Rudat [17], specifically spectral response type and some hydro-morphological characteristics, are given in Table 1. 
Table 1. Kettle holes' hydromorphological characteristics and spectral response types.

\begin{tabular}{|c|c|c|c|c|c|c|}
\hline Name & $\begin{array}{l}\text { Area } \\
\text { (ha) }\end{array}$ & Depth (m) & Algae Coverage & Water Color & Subtype & $\begin{array}{l}\text { Spectral } \\
\text { Response Type }\end{array}$ \\
\hline K1 & $\approx 0.12$ & $\approx 1 \div 1.5$ & Close to the surface & Transparent & Big shallow & $\begin{array}{l}\text { Submerged } \\
\text { vegetation }\end{array}$ \\
\hline K2 & $\approx 0.14$ & $\approx 0.5 \div 1.0$ & Close to the surface & Transparent & Big shallow & $\begin{array}{l}\text { Submerged } \\
\text { vegetation }\end{array}$ \\
\hline K4 & $\approx 0.80$ & $\approx 2.5 \div 3.5$ & Very Low & Dark green & Big deep & $\begin{array}{l}\text { Phytoplankton } \\
\text { dominated }\end{array}$ \\
\hline K5 & $\approx 0.10$ & $\approx 0.3 \div 0.5$ & Close to the surface & $\begin{array}{l}\text { 2007-Light brown } \\
\text { 2008-Transparent }\end{array}$ & $\begin{array}{l}\text { Small } \\
\text { wadeable }\end{array}$ & Mixed \\
\hline K6 & $\approx 0.25$ & $\approx 0.6 \div 1.3$ & Only on the banks & Transparent & Big shallow & $\begin{array}{l}\text { Phytoplankton } \\
\text { dominated }\end{array}$ \\
\hline K7 & $\approx 0.23$ & $\approx 0.8 \div 1.2$ & Low & Transparent & Big shallow & $\begin{array}{l}\text { Phytoplankton } \\
\text { dominated }\end{array}$ \\
\hline
\end{tabular}

\subsection{Field Sampling}

Field data were collected from six kettle holes in the period between June and October 2007 (a total of seven datasets, five of which were with spectral data). In 2008, ground truth data were collected in 10 field campaigns from five kettle holes in the period between May and September 2008. Chlorophyll was determined by using $N, N^{\prime}$-dimethylformamide (DMF) extraction as described by Porra et al. [18]. Samples were filtered using Whatman GF/F filters and incubated with $3 \mathrm{~mL}$ DMF for $12 \mathrm{~h}$ in darkness. Absorption was measured with a UV/VIS spectrophotometer (Lambda 2, Perkin Elmer) from $400 \mathrm{~nm}$ up to $750 \mathrm{~nm}$. Pigment contents $\left(\mu \mathrm{g} \cdot \mathrm{L}^{-1}\right)$ were calculated from the absorbance spectra of the extracts according to Porra et al. [18].

\subsection{Measurement of Spectral Reflectance}

A field spectrometer (ASD FieldSpec $\mathrm{HH}$ ultraviolet/visible and near-infrared (UV/VNIR)) was used to measure the upwelling radiance of the water at each sampling station during water sampling. The instrument records a continuous spectrum with $25^{\circ}$ field of view (FOV) in 512 bands, ranging from $274 \mathrm{n} \mathrm{nm}$ to $1,085 \mathrm{~nm}$ with $1,587 \mathrm{~nm}$ spectral resolution (ASD Inc.). Upwelling radiance from the water body is being retrieved as relative reflectance in relation to the down-welling radiance spectrum measured from a reference panel (Spectralon, Barium sulfate plate with approximately 100\% reflectance, 25-30 cm above the panel). At each sampling station, the reference panel was scanned first. Depending on the depth and size of the kettle hole, the spectral measurement took place either on the board of a boat or at the shoreline. The measuring unit was held above the water and oriented away from the boat side within the light propagation to minimize sun glint from waves, and far enough not to be affected by the boat shadow. In both cases data was collected at or close to the central part of the kettle hole at the height of $\approx 30 \mathrm{~cm}$ in vertical downward direction between 10:00 a.m. and 2:00 p.m. At least ten measurements (sample size) were taken from each kettle hole repetitively, which were afterwards averaged to minimize random effects. 
Following Igamberdiev et al. [3] complete reflectance datasets from all kettle holes were de-noised using discrete wavelet transformation (DWT) and then processed to volume reflectance.

\subsection{Statistical Methods}

Semi-empirical algorithms describe physical characteristics of the light in the water for the determination of the model but determination of the correlations coefficients is based on statistical analysis [16]. All models used in this study are linked to the in situ data by means of linear regression analysis to derive the semi-empirical correlation coefficients. In this way, the model is calibrated to the spatial and/or seasonal or cross-seasonal characteristics of kettle holes in the study area. In the literature, the Root Mean Square Error (RMSE) is mostly taken to describe the quality of linear regressions [19]. The RMSE is calculated for better comparison with other research results in this field of science. Within these calculations, the residues become squared, which weights the outlier as stronger. Since in this study a few samples were available for each kettle hole, the absolute Mean Deviation $\left(M D_{a}\right)$ is taken for analysis residues variations.

$R M S E$ is defined in the case of linear regression analysis as:

$$
R M S E=\left(\frac{\sum_{i=1}^{N}\left[\log \left(y_{i}^{\prime}\right)-\log \left(y_{i}\right)\right]^{2}}{N-2}\right)^{1 / 2}
$$

where $N$ is the total number of samples in the dataset, $y_{i}$ is the measured in situ value and $y_{i}^{\prime}$ is the estimated value.

Within these calculations, the residues become squared, which weights the outlier as stronger. The $R M S E$ is the distance, on average, of a data point from the fitted line, measured along a vertical line. The $M D_{a}$ is defined as the mean of the absolute deviations of a set of data divided by the data's mean $[16,19]$. For a number of samples $N$, the mean deviation is defined by:

$$
M D_{a}=\frac{1}{N} \sum_{i=1}^{N}\left|y_{i}-y_{i}^{\prime}\right|
$$

\section{Results}

\subsection{Typology of Spectral Response}

Kalettka and Rudat [17] developed a hydrogeomorphic approach for the classification and functional assessment of kettle holes. Based on the two-year analysis of field observations of various small shallow waters and their corresponding reflectance datasets, we proposed the following typology of spectral response [20]: Submerged vegetation, Phytoplankton dominated and Mixed type. Figure 2 shows the examples of volume reflectance from the kettle holes collected in 2007 and 2008 according to the proposed typology. The calculation of the volume reflectance from the surface reflectance is given in Igamberdiev et al. [3].

The spectral signatures from the Submerged vegetation type of kettle holes are comparable to reflection from vegetation cover (e.g., in Jensen [6]) with a smaller magnitude. Figure 2(a) shows an 
example for this type of reflectance taken from kettle hole K1.The signal is most likely caused by high algae content. In K1, algae grew almost to the surface. The reflectance in the green electromagnetic spectrum (500-600 nm) is characterized by the first chlorophyll peak (i.e. the algae spectral response from the bottom). The Red/NIR range $(650-850 \mathrm{~nm})$ has the highest magnitude and two distinctive reflection peaks one following the other. Mostly, the first Red/NIR range peak is higher than the second. The results of this study showed that spectral response from kettle hole $\mathrm{K} 2$ also belongs to the Submerged vegetation type [3].

Figure 2. (a-c) Kettle holes' volume reflectance collected in 2007 and 2008 according to proposed typology with example of field images (sample size $n \geq 10$ ). (d) Field images of the kettle holes.

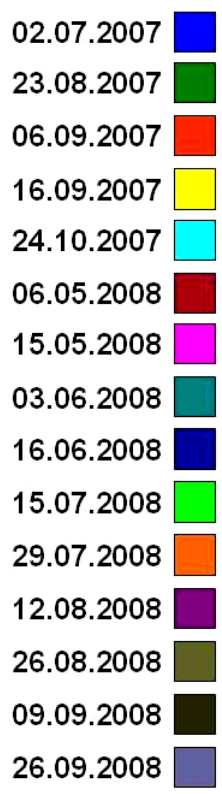

02.07.2007

23.08.2007

06.09.2007

16.09.2007

24.10.2007

06.05.2008

15.05.2008

03.06.2008

16.06.2008

15.07.2008

29.07.2008

12.08.2008

26.08.2008

09.09 .2008

26.09.2008

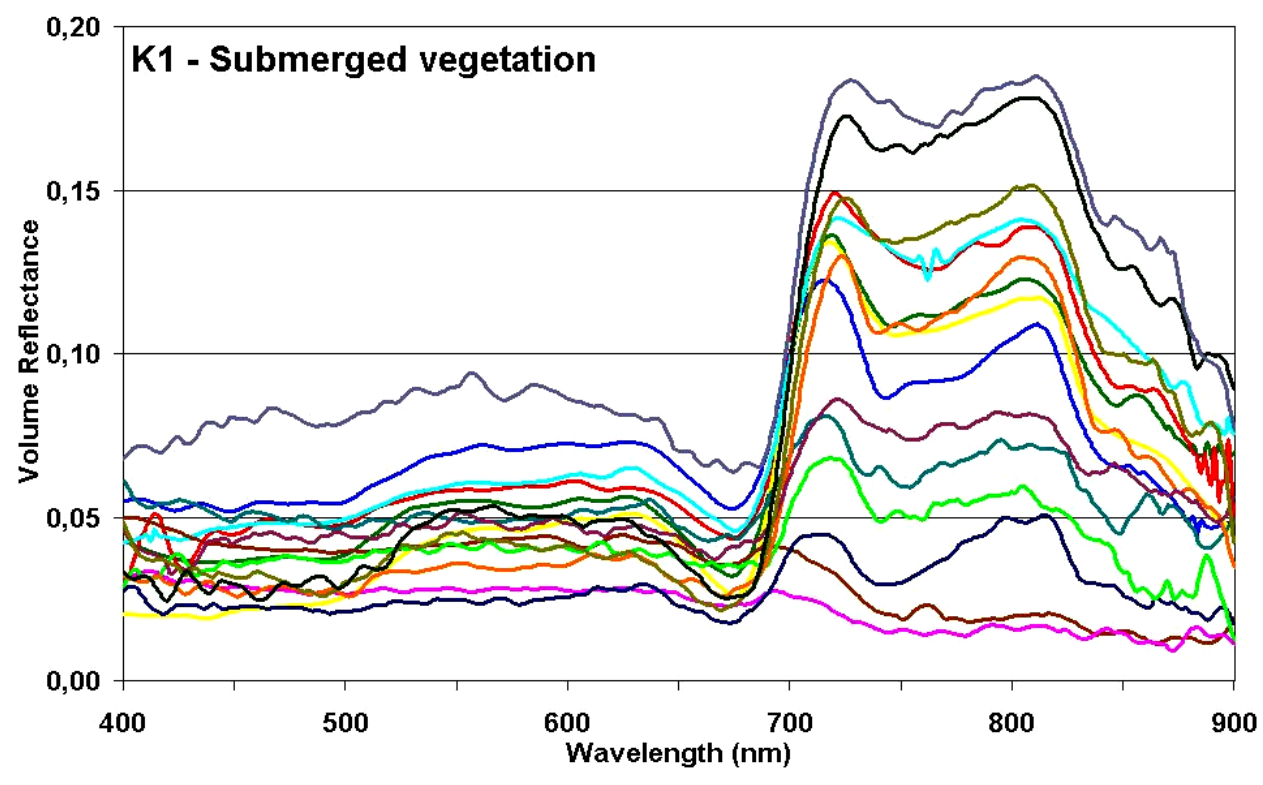

(a)

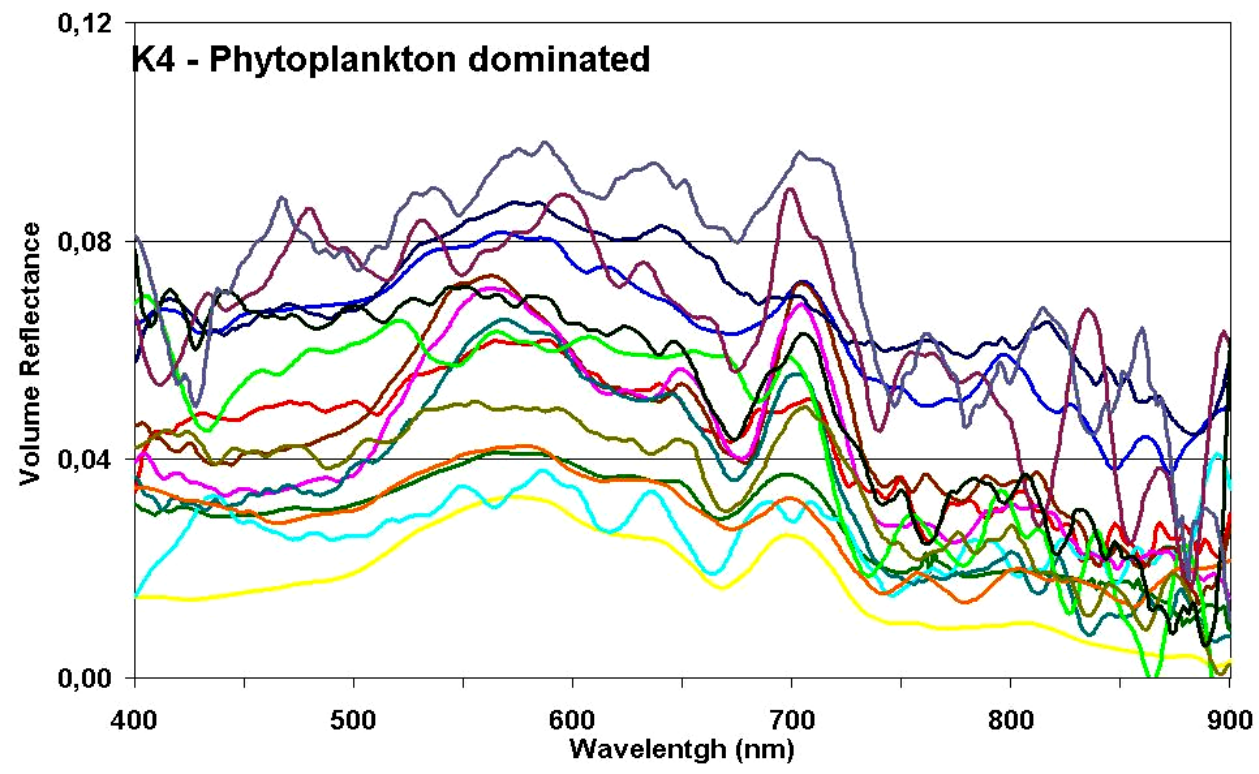

(b) 
Figure 2. Cont.

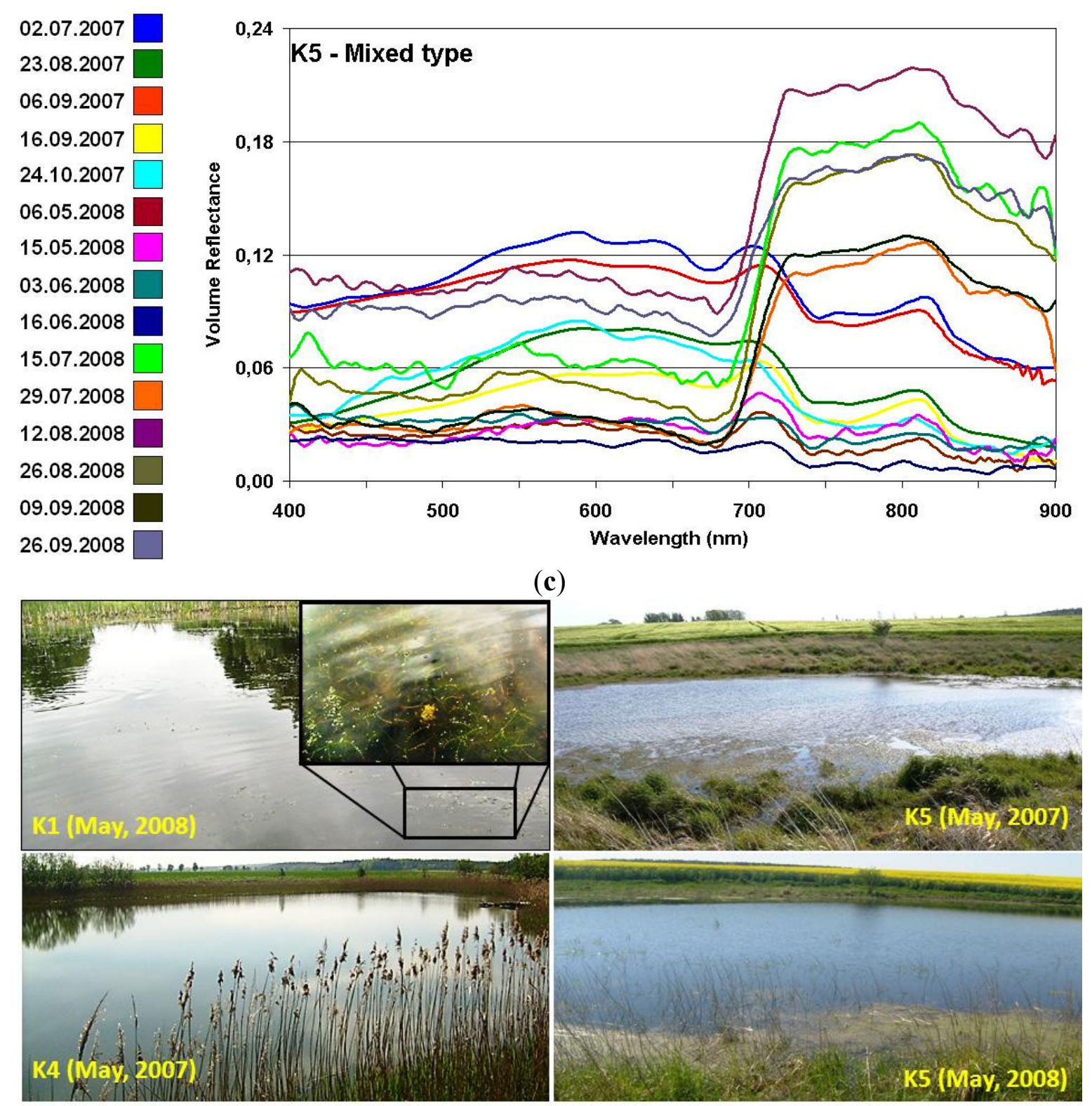

(d)

The reflectance curves from the Phytoplankton dominated type exhibit a distinct signal in the green electromagnetic spectrum range, which can only be explained by the presence of phycobilins typical for blue-green algae. The magnitude of reflection is comparable with the Red/NIR region. The red-edge peak can be distinguished in all spectral curves. This type of reflection peak at $700 \mathrm{~nm}$ is commonly used in remote sensing for chlorophyll concentration determination [12,21]. This type of spectra is characterized by high signal variation at the range in 750-900 nm, which consequently stabilized at $930 \mathrm{~nm}$ or $970-980 \mathrm{~nm}$ regions (depends on turbidity), as well as by the magnitude of reflectance that is two times lower compared to the Submerged vegetation type. Spectral response from kettle hole K4 is shown on Figure 2(b) as an example for this type of reflections. Regardless of the denoising techniques application [3], the reflectance curves of K4 still have high variations caused by windy conditions during the measurements. This noise can be a limiting factor for spectral signatures classification and biomass data retrieval correlations. Spectral signatures from kettle holes K6 and K7 have the same type of curves. 
The Mixed type consists of spectral curves from both Submerged vegetation and Phytoplankton dominated reflection types. This mixed spectral response is due to alga bloom caused by agricultural practice and nutrients input in a catchments area of the kettle hole [3]. For instance, analysis of two-year spectral data from kettle hole K5 revealed mixed reflectance (Figure 2(c)). In 2007, K5 had a brown water color and, consequently, low transparency. In 2008, the situation changed due to a different amount of precipitation in the summer period. In the research area, the summer of 2007 provided more precipitation than the summer of 2008 which subsequently influenced the amount of water that reached all water bodies, including kettle holes (Figure 3). The total suspended solids (TSS) values of 7 June and 2 July 2007 were $111 \mathrm{mg} \cdot \mathrm{L}^{-1}$ and $100 \mathrm{mg} \cdot \mathrm{L}^{-1}$, respectively, with an average value for the whole season of $36 \mathrm{mg} \cdot \mathrm{L}^{-1}$ (Table 2) [3]. In summer/autumn of 2008, the average TSS values were around $14-15 \mathrm{mg} \cdot \mathrm{L}^{-1}$. Therefore, the spectral signatures of $\mathrm{K} 5$ have two types of reflectance shapes: those influenced by phytoplankton domination, and coupled with turbid waters and algae. For the whole field campaign of 2007 and the beginning of 2008, pond K5 had light brown (turbid)-colored water (Table 1). Consequently, the spectral response from moderately turbid water is described by Doxaran et al. [22]. Starting from June-July 2008, the smaller amount of rain (and subsequent smaller input of sediments) caused intensive growth of algae (Figure 3). The analysis of spectral signatures of K5 shows how the changes of the water leaving signal take place in small shallow water bodies on a hyperspatial scale, and highlights their influence on the remote sensing signal (Figure 3(c)).

Table 2. Chlorophyll-a (P1 in $\left.\mu \mathrm{g} \cdot \mathrm{L}^{-1}\right)$, total chlorophyll (P2 in $\mu \mathrm{g} \cdot \mathrm{L}^{-1}$ ) and total suspended solids (P3 in $\mathrm{mg} \cdot \mathrm{L}^{-1}$ ) collected for all studied kettle hole (for 2007-08 season).

\begin{tabular}{|c|c|c|c|c|c|c|c|c|c|c|c|c|c|c|c|}
\hline \multirow{2}{*}{ Date } & \multicolumn{3}{|c|}{ K1 } & \multicolumn{3}{|c|}{ K4 } & \multicolumn{3}{|c|}{ K5 } & \multicolumn{3}{|c|}{ K6 } & \multicolumn{3}{|c|}{ K7 } \\
\hline & P1 & P2 & P3 & P1 & P2 & P3 & P1 & P2 & P3 & P1 & P2 & P3 & P1 & P2 & P3 \\
\hline 07.06.07 & 15.8 & 20.0 & 5.7 & 33.4 & 41.7 & 2.3 & 94.3 & 111.4 & 21.3 & 17.3 & 19.4 & 9.4 & 1.9 & 3.0 & 2.0 \\
\hline 02.07 .07 & 4.6 & 9.5 & 2.0 & 64.6 & 95.3 & 13.8 & 62.0 & 100.6 & 12.3 & 3.2 & 5.5 & 6.0 & 4.6 & 9.5 & 2.0 \\
\hline 23.08 .07 & 1.9 & 3.1 & 1.6 & 43.2 & 62.7 & 3.9 & 4.2 & 6.8 & 8.7 & 4.5 & 7.3 & 2.4 & 1.9 & 3.1 & 1.6 \\
\hline 06.09.07 & 2.1 & 2.5 & 1.7 & 80.9 & 109.9 & 6.0 & 5.0 & 11.0 & 7.4 & 54.8 & 55.0 & 5.8 & 2.1 & 2.5 & 1.7 \\
\hline 16.09 .07 & 5.1 & 10.6 & 1.7 & 35.0 & 42.3 & 12.0 & 2.3 & 3.5 & 11.8 & 14.9 & 20.9 & 2.4 & 5.1 & 10.6 & 1.7 \\
\hline 24.10 .07 & 2.4 & 2.9 & 4.7 & 83.7 & 93.0 & 10.4 & 2.6 & 3.4 & 7.0 & 6.5 & 6.9 & 2.8 & 2.4 & 2.9 & 4.7 \\
\hline 06.05 .08 & 1.2 & 1.6 & 2.1 & 108.0 & 110.8 & 5.2 & 7.0 & 7.0 & 3.2 & 2.2 & 3.2 & 1.7 & 1.2 & 1.6 & 2.1 \\
\hline 15.05 .08 & 2.5 & 3.2 & 2.5 & 78.6 & 102.9 & 13.9 & 3.4 & 4.6 & 2.6 & 5.9 & 10.2 & 3.1 & 2.5 & 3.2 & 2.5 \\
\hline 03.06 .08 & 6.4 & 7.5 & 1.9 & 59.0 & 61.3 & 17.4 & 17.0 & 18.6 & 5.3 & 9.5 & 10.2 & 2.3 & 6.4 & 7.5 & 1.9 \\
\hline 16.06 .08 & 6.3 & 6.8 & 4.3 & 30.0 & 34.8 & 5.9 & 8.5 & 9.4 & 2.2 & 4.2 & 6.1 & 1.5 & 6.3 & 6.8 & 4.3 \\
\hline 15.07.08 & 5.2 & 7.1 & 4.4 & 79.2 & 87.1 & 7.2 & 2.5 & 3.3 & 9.2 & 5.3 & 7.1 & 1.4 & 5.2 & 7.1 & 4.4 \\
\hline 29.07 .08 & 3.2 & 4.3 & 4.0 & 32.9 & 40.2 & 4.8 & 4.4 & 6.2 & 2.3 & 3.2 & 4.0 & 0.8 & 3.2 & 4.3 & 4.0 \\
\hline 12.08 .08 & 3.3 & 4.9 & 3.0 & 156.1 & 224.7 & 11.7 & 18.9 & 33.6 & 6.5 & 5.0 & 7.0 & 1.4 & 3.3 & 4.9 & 3.0 \\
\hline 26.08 .08 & 4.4 & 6.6 & 1.1 & 129.2 & 145.3 & 11.6 & 5.4 & 6.1 & 4.9 & 10.3 & 12.2 & 3.9 & 4.4 & 6.6 & 1.1 \\
\hline 09.09.08 & 2.7 & 5.3 & 1.3 & 181.0 & 218.9 & 13.3 & 23.4 & 28.5 & 6.0 & 4.3 & 8.7 & 0.8 & 2.7 & 5.3 & 1.3 \\
\hline 26.09 .08 & 3.6 & 6.8 & 1.8 & 143.0 & 171.9 & 8.8 & 15.1 & 24.1 & 8.4 & 3.6 & 5.2 & 0.9 & 3.6 & 6.8 & 1.8 \\
\hline
\end{tabular}


Figure 3. Daily precipitation data from a nearby weather station (Greifswald) during sampling period (May-October of 2007 and 2008).

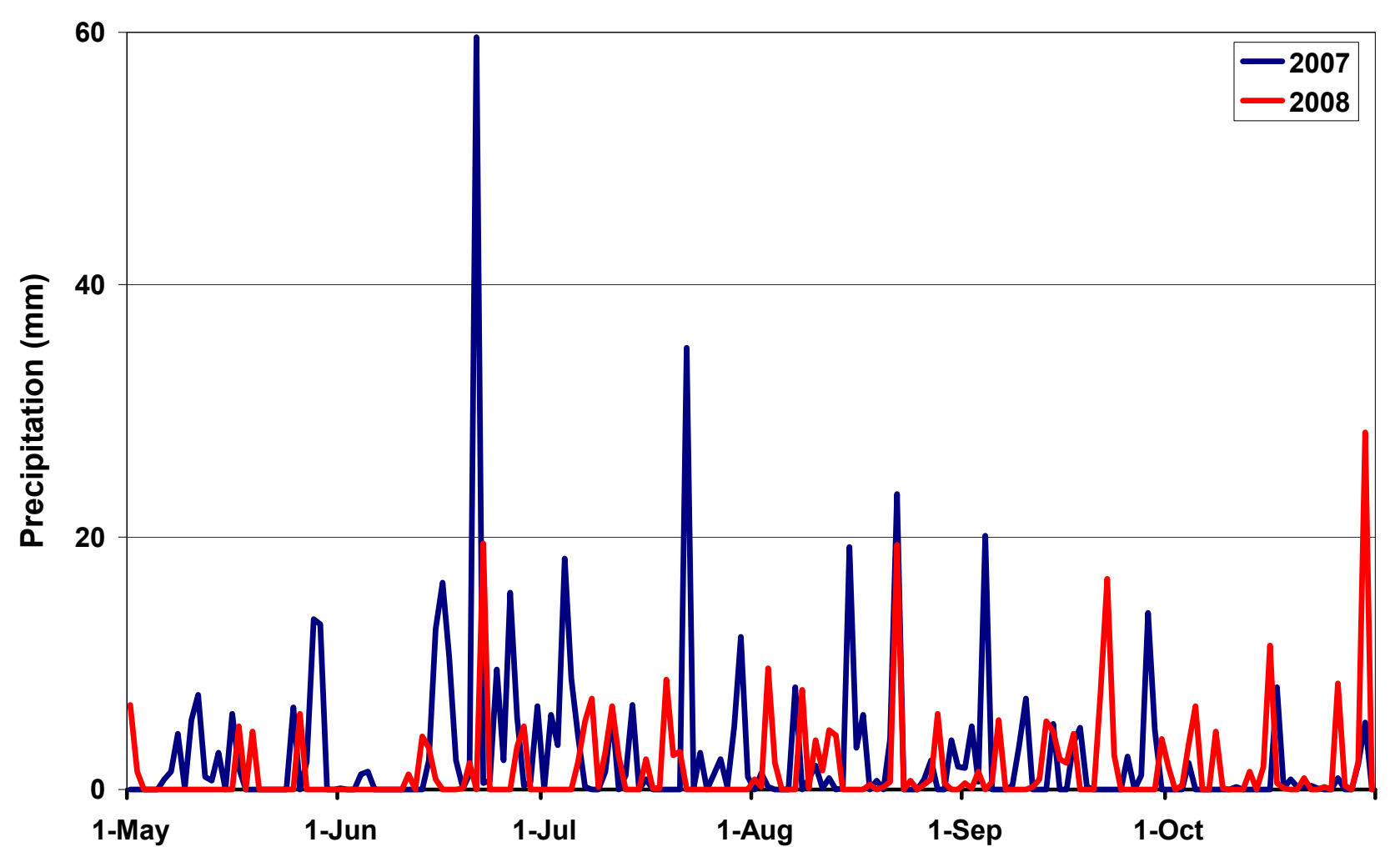

\subsection{Spectral Algebra Algorithms and Biomass Concentrations}

Seasonal and cross-seasonal de-noised volume reflectance from all kettle holes has been tested for existing semi-empirical algorithms based on spectral algebra [16,23] and first derivative analysis [24]. The ratio between the minimum near $670 \mathrm{~nm}$ and the maximum near $700 \mathrm{~nm}$ was successfully applied to the data obtained in highly diverse aquatic ecosystems dominated by different algal assemblages [23,25].

The height of the peak above a baseline between $670 \mathrm{~nm}$ and $750 \mathrm{~nm}$ depends mainly on phytoplankton density and was used as its quantitative measure [23]. In the case of K1, K2 and K6, spectral signatures are highly influenced by phytoplankton and correspond to the vegetation reflectance shape with lower magnitudes. From this type of curve, the maximum magnitude near $700 \mathrm{~nm}$ produces the best results [3].

The effectiveness of derivative analysis in estimating chlorophyll-a concentration in coastal waters has been tested by Han [26]. This study proved that the derivative spectra were relatively independent of wave effects and therefore continued to show the absorption features of chlorophyll under windy conditions. The spectral regions of derivative spectra $630-645 \mathrm{~nm}, 660-670 \mathrm{~nm}, 680-687 \mathrm{~nm}$ and $700-735 \mathrm{~nm}$ were found to be potential regions where the first derivatives can be used to estimate chlorophyll concentration.

The theory of chlorophyll-laden waters showed that decreasing CHL absorption and increasing absorption of pure water is the major factor influencing the reflectance peak near $700 \mathrm{~nm}[27,28]$. Thus, the vast majority of investigations were dedicated to establishing correlations between CHL and remotely sensed data. At the same time, Kneubuehler et al. [16] determined $\approx 0 \mu \mathrm{g} \cdot \mathrm{L}^{-1} \mathrm{CHL}$ 
concentration for two samples of the same lake, whereas measured spectra showed the presence of at least small contents of chlorophyll. However, the majority of the phytoplankton consist of cyanobacteria, and the main part of the Chlorophyll-a is likely of cyanobacterial origin [29], so laboratory-measured TCHL was used for the regression analysis, assuming that TCHL represents the concentration of exclusively CHL. By using TCHL, the same assumption was followed. Therefore, algorithms based on spectral algebra and derivative analyses were applied for both biomass concentrations values, i.e., CHL and TCHL. Figure 4 illustrates the first derivative spectra of kettle holes K1, K4 and K5 calculated from the volume reflectance for the 2007 and 2008 datasets.

\subsection{Derivative Reflectance Analysis}

Figure 4(a) illustrates the first derivative spectra of kettle hole K1 calculated from the volume reflectance for the 2007 and 2008 datasets. The first derivatives for steeper slopes of reflectance curves tended to have higher absolute values. Note that the lower variations of the derivative spectra as compared to original reflectance in Figure 2(a). The peak in the 680-700 nm range which corresponds to the so-called Peak near $700 \mathrm{~nm}$ or Red-edge can clearly be seen.

The chlorophyll-laden peak at around $700 \mathrm{~nm}$ is also clearly recognizable on Figure 4(b) from the first derivative spectra of kettle hole K4 extracted from normalized reflectance of 2007 and 2008 datasets. K4 can be considered as a small lake; its volume reflectance and derivative spectra act accordingly. As is expected, similar to volume reflectance, the magnitude of derivative spectra from $\mathrm{K} 4$ is lower than from $\mathrm{K} 1$.

Figure 4. First derivative spectra of kettle holes K1, K4 and K5 calculated from volume reflectance from 2007 and 2008 datasets.

\begin{tabular}{l}
02.07 .2007 \\
23.08 .2007 \\
06.09 .2007 \\
16.09 .2007 \\
24.10 .2007 \\
\hline
\end{tabular}

26.09.2008

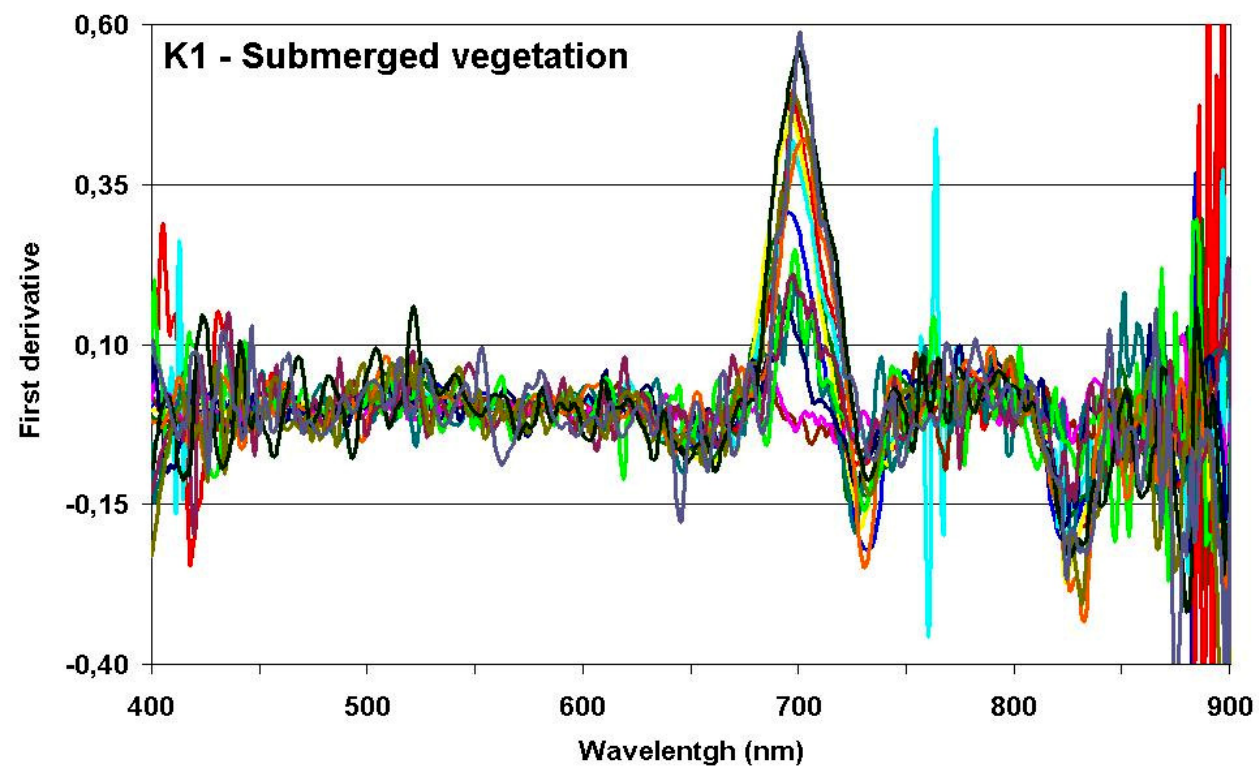

(a) 
Figure 4. Cont.

02.07 .2007
23.08 .2007
06.09 .2007
16.09 .2007
24.10 .2007
06.05 .2008
15.05 .2008
03.06 .2008
16.06 .2008
15.07 .2008
29.07 .2008
12.08 .2008
26.08 .2008
09.09 .2008

02.07.2007

23.08.2007

06.09.2007

16.09 .2007

24.10.2007

06.05.2008

15.05.2008

03.06 .2008

16.06.2008

15.07 .2008

29.07.2008

12.08 .2008

26.08 .2008

09.09 .2008

26.09.2008

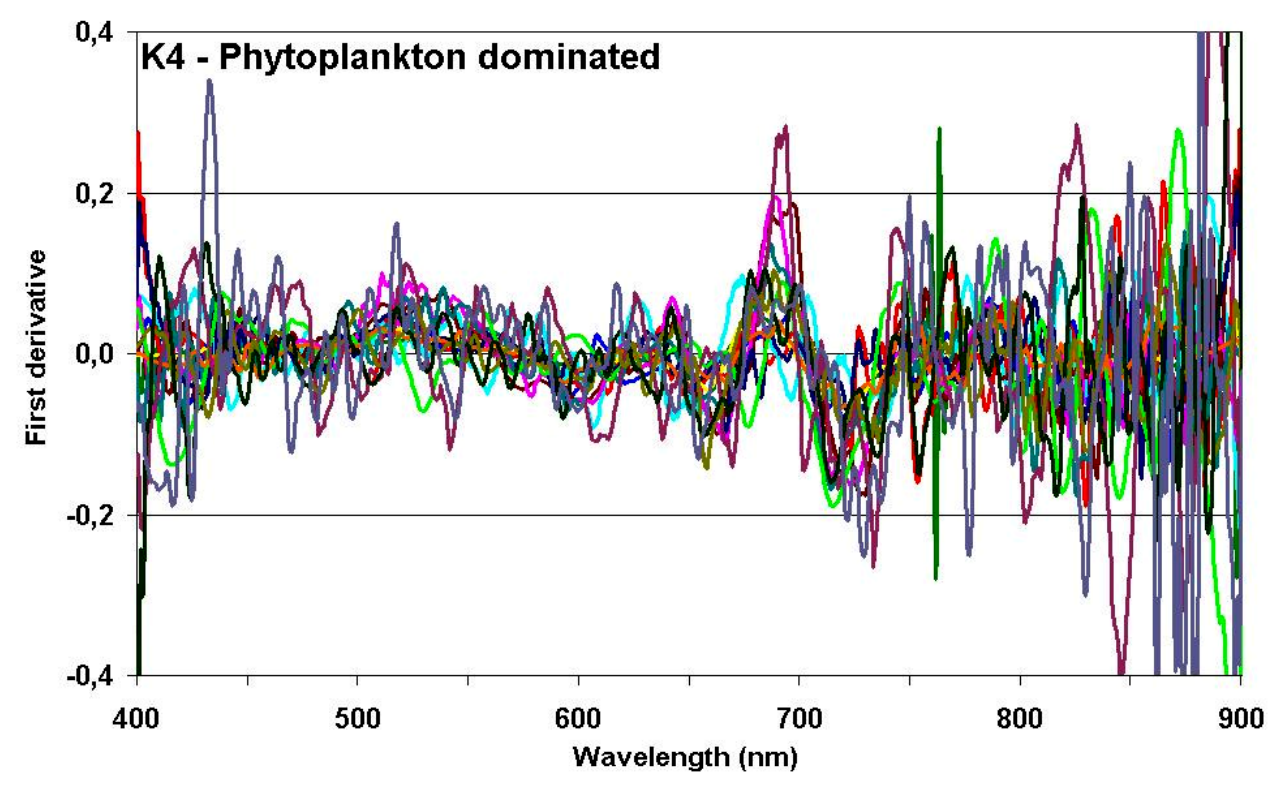

(b)

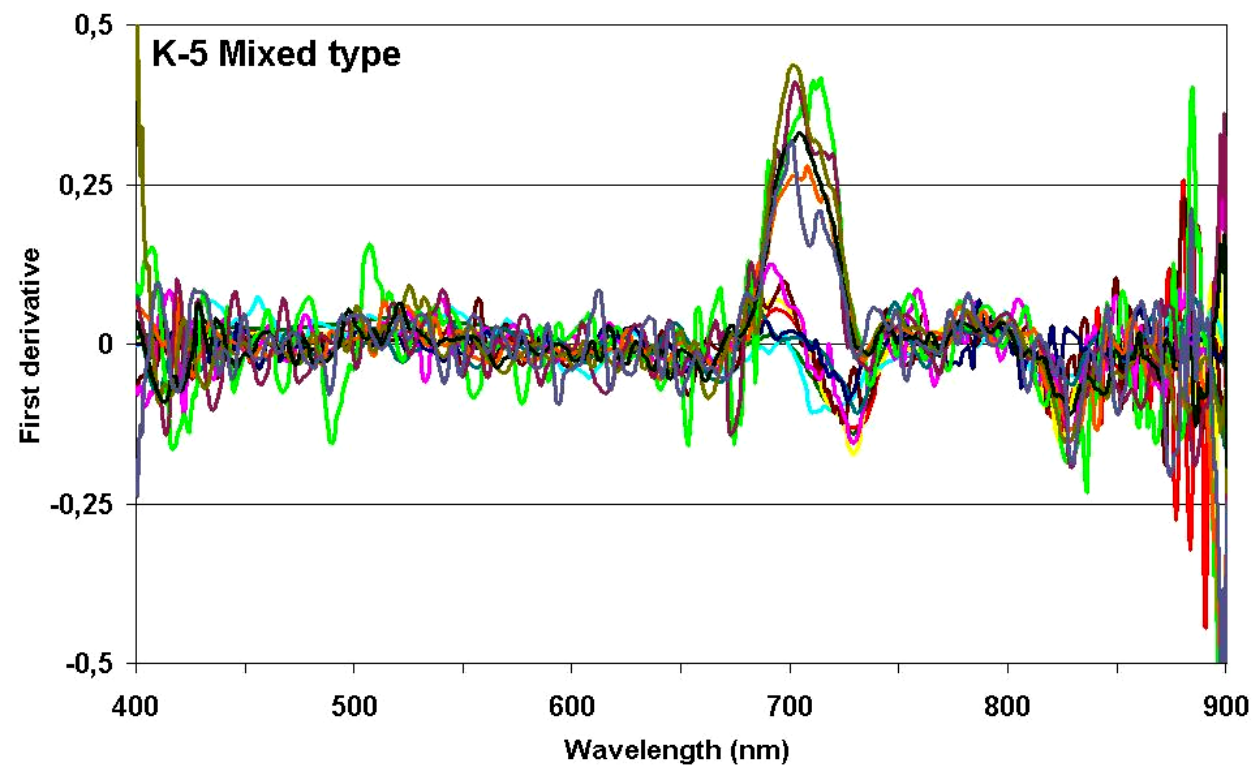

(c)

Kettle hole K5 was a very shallow kettle hole $(30-50 \mathrm{~cm})$ with high algae content. It had brown-colored waters in season 2007 and was transparent the next year. These changes can be easily seen in the spectral signatures of both years caused by the amount of precipitation (Figure 3). Consequently, the same types of change have affected the derivative spectra. Figure 4(c) illustrates derivative spectra from K5 calculated from volume reflectance. Two chlorophyll reflectance peaks near $700 \mathrm{~nm}$ with different magnitudes can be observed in the derivative spectra: the first with a lower magnitude caused by turbid waters in 2007 and beginning of 2008; and the second with a higher magnitude influenced by algae-dominated shallow water. The first confirms the decreasing chlorophyll-a absorption and increasing absorption of water content, which have the major influence on the red-edge reflectance peak in chlorophyll-a laden waters [30]. Therefore, depending on water content and domination type, the red-edge peak pattern is modified either within season or inter-seasonally. 


\subsection{Application of Remote Sensing Techniques for Chlorophyll Estimation}

The radar diagrams of the best linear correlation coefficients between chlorophyll concentrations and remote sensing data are shown on Figure 5. CHL and TCHL estimation from volume reflectance and derivative spectra was based on following methodologies frequently described in the literature:

(1) Spectral algebra (application of Peak Magnitude, Magnitude of the Peak Above a Baseline and the Position of the Peak Algorithms). Source: Gitelson et al. [23], Kneubuhler et al. [16] and Igamberdiev et al. [20];

(2) Pearson's correlation (testing the reflectance value at a specific wavelength). Source: Jiao et al. [31], Murphy et al. [32] and Wang et al. [33].

The analysis of remote sensing data from the Submerged vegetation type shows that the best linear regression coefficients for the season of 2007 were between TCHL and the volume reflectance and derivative spectra (Figure 5(a)). The best correlation algorithms using volume reflectance for the season of 2007 were Peak Magnitude and Magnitude at $721 \mathrm{~nm}$ [3], whereas for derivative spectra, the magnitude is at $697 \mathrm{~nm}$. In the season of 2008, correlation with TCHL is still very high; nevertheless, the best linear regressions are with CHL values. Therefore, cross-seasonal correlation with CHL concentration produces higher linear regression values compared with TCHL concentrations. This is probably caused by the differences in the number of samples in the season of 2007 (5 samples) and 2008 (10 samples). The best algorithms for 2008 and 2007-08 (cross-seasonal correlations) seasons are a Peak Magnitude above a Baseline and Magnitude at $697 \mathrm{~nm}$ between CHL and volume reflectance $\left(R^{2}=0.93\right)$ and derivative spectra $\left(R^{2}=0.87\right)$, respectively.

Figure 5. Radar diagrams of the correlation coefficients calculated for biomass concentrations' estimation using various algorithms for kettle holes K1, K4 and K5 (n = 15 of 2007-08).

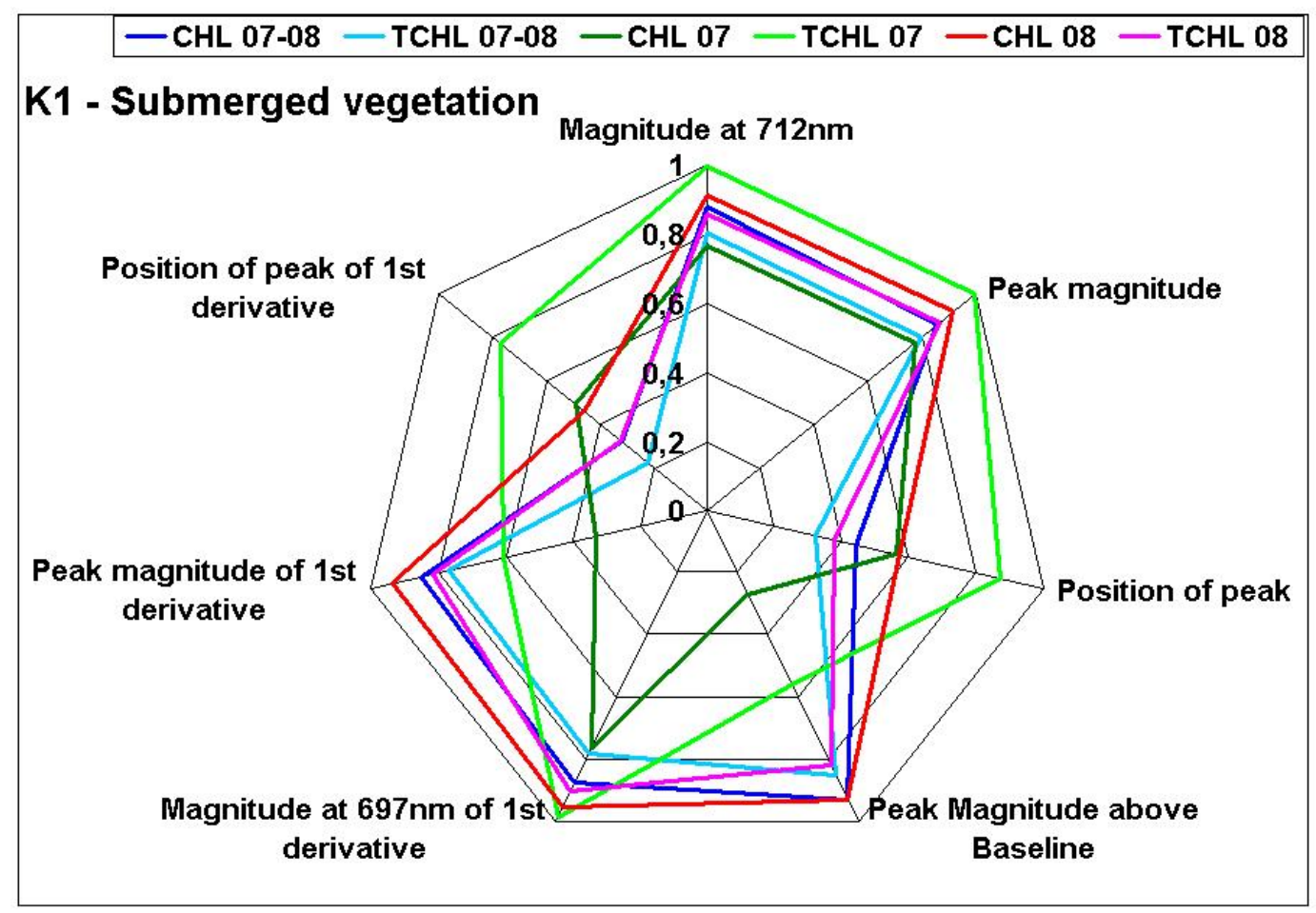

(a) 
Figure 5. Cont.

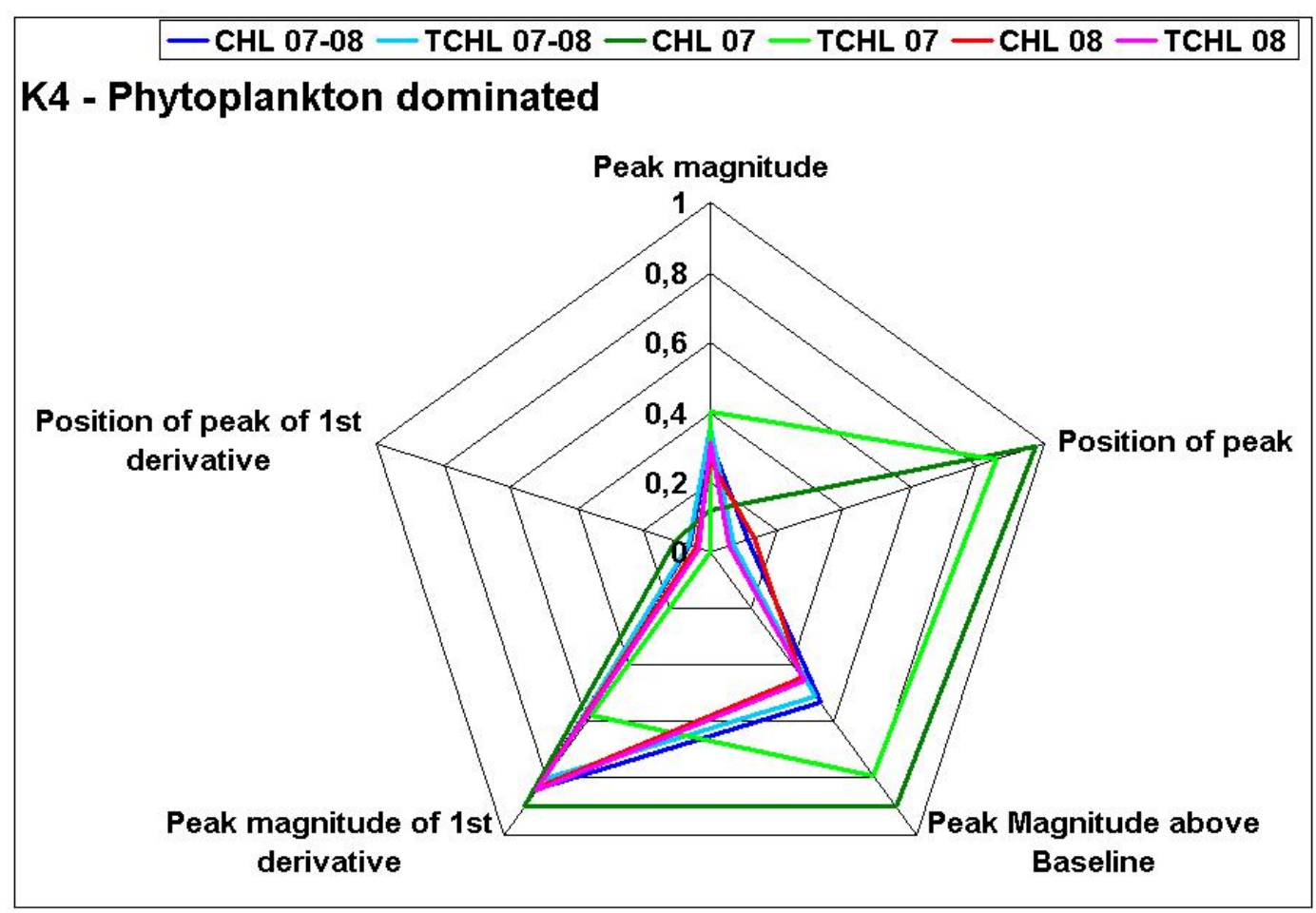

(b)

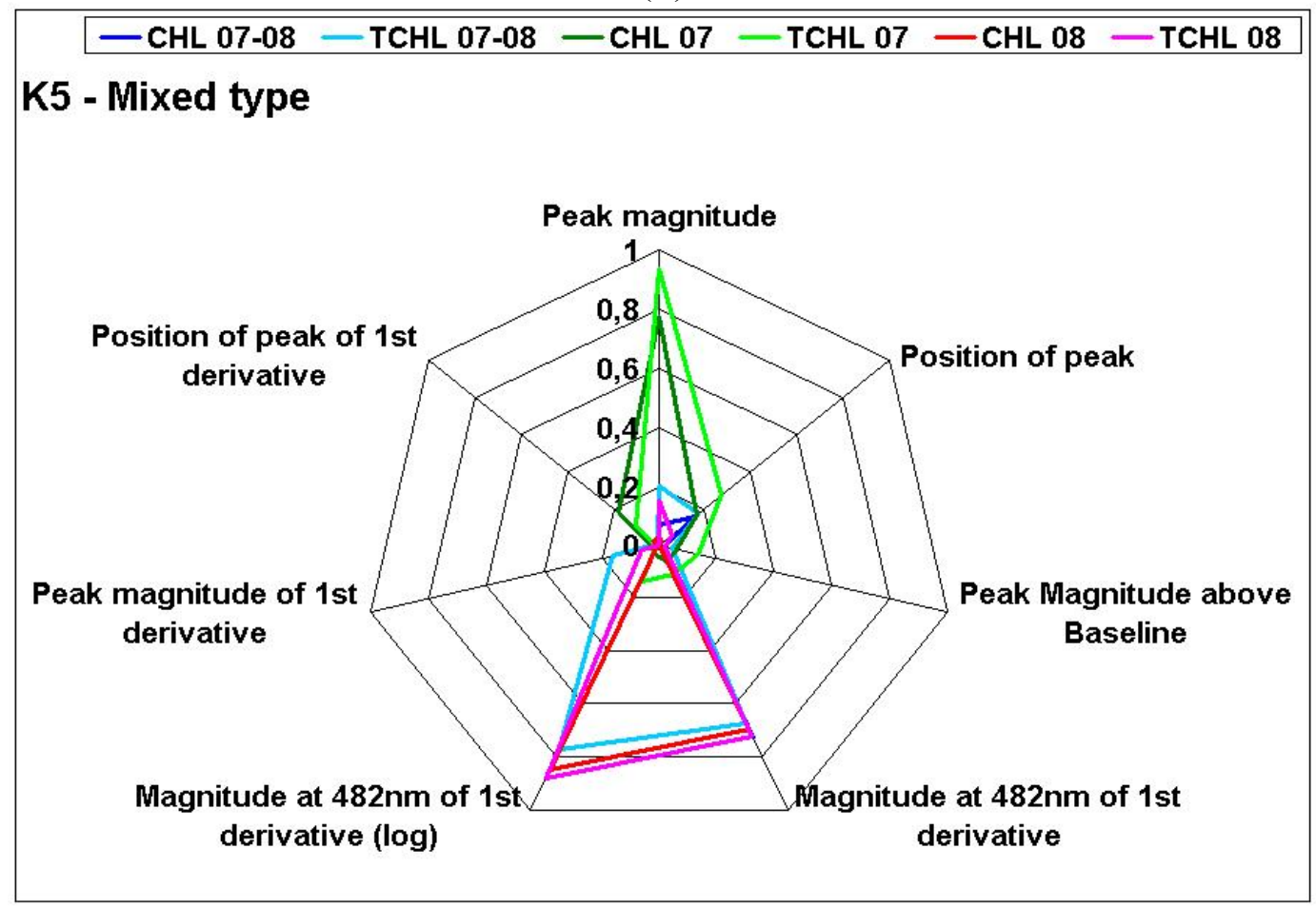

(c)

Volume reflectance of kettle holes K4 (Phytoplankton dominated type) in 2007 is correlated best with CHL using the classic algorithms Peak Magnitude Above a Baseline and Position of Peak (Figures 5(b) and 6(b)). Derivative spectra of 2007 and biomass data perform the best correlation using the Peak Magnitude algorithm. For the season of 2008, the linear regression analyses between the derivative spectra and TCHL produces a high determination coefficient using the Peak Magnitude algorithm. Correlation for CHL $\left(R^{2}=0.83\right)$ is slightly lower than TCHL $\left(R^{2}=0.84\right)$. Finally, the best 
cross-seasonal (2007-08) correlation uses derivative spectra and the Peak Magnitude algorithm $\left(R^{2}=0.84\right)$ despite high noise influences. This was expected because the hydro-morphological characteristics of this kettle hole could be compared to the shallow lakes with moderate chlorophyll and TSS concentrations, as described by Scheffer [29]. Han and Rundquist [34] found that for such lakes, the application derivative analysis approach produced the best correlations.

Coefficients of linear determinations between volume reflectance and biomass concentrations produced low values for the season of 2008 and, consequently, for cross-seasonal combination (Mixed type). Only the season of 2007 has stable and high correlations for a chlorophyll absorption range of 680-690 nm. Similar to volume reflectance correlations between TCHL and derivative spectra, they are consistent only for $2007\left(R^{2}=0.94\right)$. Although the correlations with derivative spectra are better than with volume reflectance, the cross-seasonal linear regression coefficients are still very low $\left(0.1 \leq R^{2} \leq 0.3\right)$.

The only stable correlation is at $482 \mathrm{~nm}$ with derivative spectra. Derivative spectra in this wavelength are an interaction zone in the visual region of light between the blue $(400-500 \mathrm{~nm})$ and green (500-600) ranges. At the same time, derivative spectra are an objective tool in isolating the absorption features of phytoplankton [35]. In Figure 2(c), it is seen that the reflections shapes are similar for both seasons in the green electromagnetic spectrum. Therefore, the best linear regression coefficients were calculated using Magnitude at $482 \mathrm{~nm}$ of 1 st derivative algorithm $\left(R^{2}=0.73\right)$. Analysis of correlation revealed that K5's derivative reflection at this wavelength has a higher correlation with chlorophyll content based on logarithmic distribution (Figure 6(c,d)).

Figure 6. Received correlations between various algorithms and biomass concentration for kettle holes K1, K4 and K5. Note scale, axes and algorithms differences.

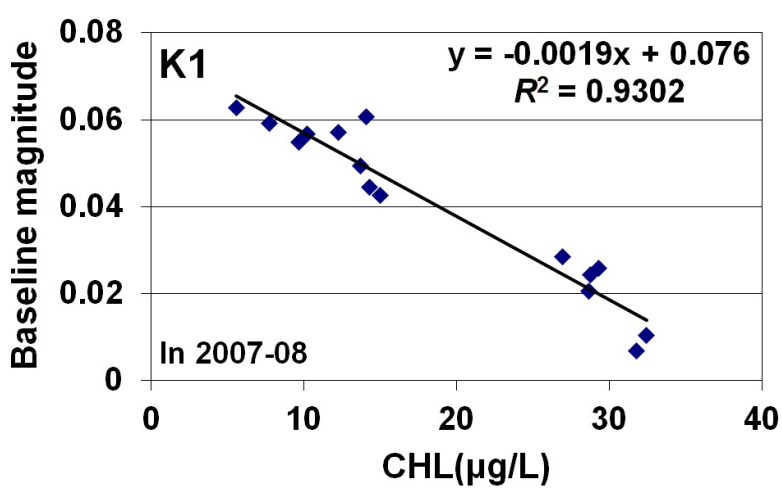

(a)

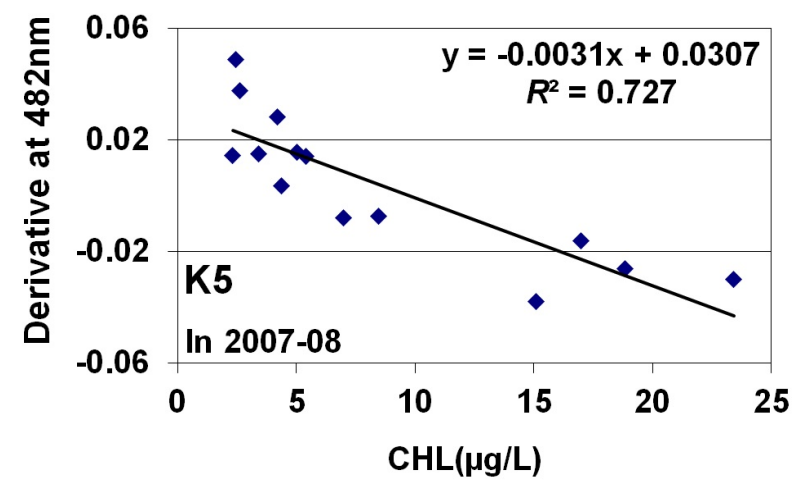

(c)

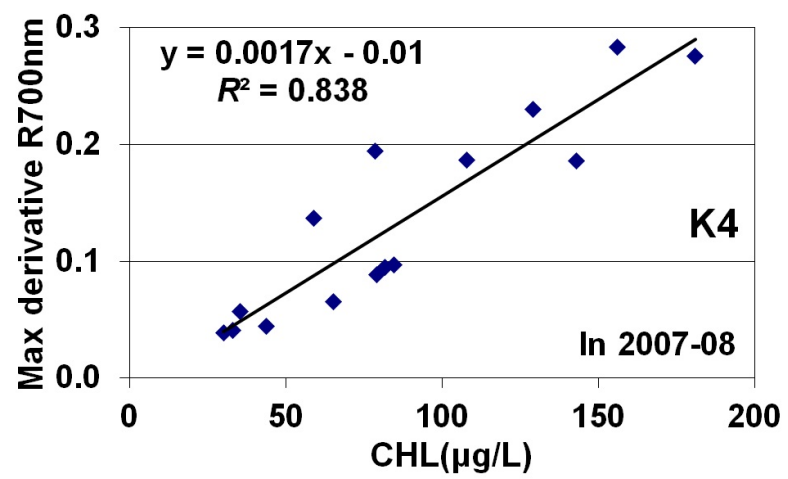

(b)

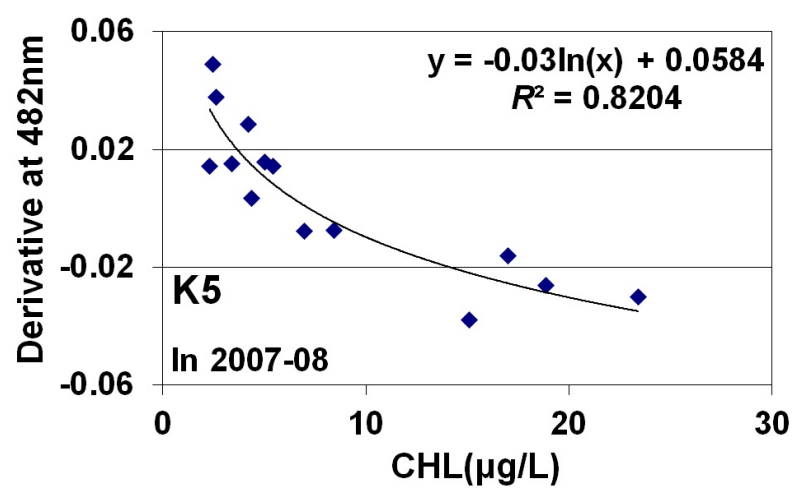

(d) 
The application of logarithmic and power functions is a part of the statistical analysis also used in regression models between in situ measured chlorophyll concentration and reflectance derived at various wavelengths $[31,36]$.

\subsection{Analysis of Biomass Estimation Algorithms Accuracy}

Table 3 shows the accuracy of the best cross-seasonal algorithms for all studied kettle holes. The results of accuracy assessment of the best cross-seasonal algorithms reveal that despite good and, in some cases, high seasonal correlations with TCHL (e.g., kettle hole K1 with $R^{2}=0.997$ for Peak Magnitude algorithm in the season of 2007), application CHL as a water quality parameter produces better results. In almost all kettle holes, cross-seasonal correlations with parameter CHL have higher values than TCHL.

Table 3. Accuracy assessment of the best cross-seasonal algorithms for all studied kettle holes ( $n=15$ for $2007-08$ season, only for K $2 n=5$ in 2007).

\begin{tabular}{|c|c|c|c|c|c|c|}
\hline $\begin{array}{l}\text { Kettle } \\
\text { Hole }\end{array}$ & $\begin{array}{l}\text { Spectral Response } \\
\text { Type }\end{array}$ & Algorithm & $\begin{array}{l}\text { Biomass } \\
\text { Type }\end{array}$ & $R^{2}$ & $\begin{array}{l}\text { RMSE } \\
\left(\mu \mathrm{g} \cdot \mathbf{L}^{-1}\right)\end{array}$ & $\mathbf{M D}_{\mathrm{a}}$ \\
\hline \multirow{2}{*}{ K1 } & \multirow{2}{*}{ Submerged vegetation } & Peak Magnitude above a Baseline & CHL & 0.93 & 0.088 & 2.09 \\
\hline & & Magnitude at $697 \mathrm{~nm}$ of 1 st derivative & CHL & 0.87 & 0.11 & 3.00 \\
\hline \multirow{2}{*}{ K2 } & \multirow{2}{*}{ Submerged vegetation } & Magnitude at $743 \mathrm{~nm}$ & CHL & 0.98 & 0.05 & 0.09 \\
\hline & & Magnitude at $697 \mathrm{~nm}$ of 1 st derivative & CHL & 0.82 & 0.14 & 0.31 \\
\hline K4 & $\begin{array}{l}\text { Phytoplankton } \\
\text { dominated }\end{array}$ & Peak Magnitude of 1st derivative & CHL & 0.84 & 0.11 & 16.65 \\
\hline \multirow{2}{*}{ K5 } & \multirow{2}{*}{ Mixed } & $\begin{array}{l}\text { Magnitude at } 482 \mathrm{~nm} \text { of } 1 \text { st derivative } \\
\text { (linear) }\end{array}$ & CHL & 0.73 & 0.30 & 3.46 \\
\hline & & $\begin{array}{l}\text { Magnitude at } 482 \mathrm{~nm} \text { of } 1 \text { st derivative } \\
\text { (logarithmic) }\end{array}$ & CHL & 0.82 & 0.16 & 2.39 \\
\hline K6 & $\begin{array}{l}\text { Phytoplankton } \\
\text { dominated }\end{array}$ & Peak Magnitude of 1st derivative & TCHL & 0.59 & 0.52 & 8.70 \\
\hline \multirow{2}{*}{ K7 } & Phytoplankton & Peak Magnitude above a Baseline & CHL & 0.85 & 0.09 & 0.52 \\
\hline & dominated & Peak Magnitude of 1 st derivative & $\mathrm{CHL}$ & 0.76 & 0.13 & 0.81 \\
\hline
\end{tabular}

The study of spectral algebra algorithms based on volume reflectance and derivative spectra shows that in spite of a high variety of hydro-morphological, physical and bio-ecological factors influencing upwelling radiance from water bodies, the application of the derivative analysis approach produces stable correlations with chlorophyll concentrations. On the other hand, linear regression between CHL and the Peak Magnitude algorithm gives consistent correlation for high algae content in kettle holes. At low algae content, Peak Magnitude Above a Baseline algorithm gives the best results as, for example, with kettle hole K7.

The methods based on the reflectance values at a specific wavelength are highly applicable for algae-dominated ponds, like for kettle holes K1, K2 and K5. For a "typical small lake" with moderately turbid water, K4 application of derivative analysis approach is the best methodology (the 
derivative analysis is able to reduce influence of suspended sediment on water leaving reflectance; Han [26]).

Kettle hole K6 had the worst correlation coefficients out of all the ponds. A study of linear correlations coefficients from this kettle hole reveals that spectral data collection in overcast weather conditions is still noise affected despite the air-water correction and de-noising. This type of kettle hole, due to hydro-morphological characteristics (Table 1), has an immediate response from agricultural activities from surrounding areas. Derivative spectra have a good correlation for 2007 [3], but are low for 2008 and, consequently, for the 2007-08 seasons. Possible reasons for low correlation in the 2008 dataset are difficulties in some days of data collection caused by shifting the boat (i.e., handheld spectrometer) from the collecting point due to strong winds. Nevertheless, the promising approach for this type of kettle hole is the application of derivative analysis.

\section{Conclusions}

The study results show that the upwelling radiance of kettle holes is highly influenced by the variability of hydro-morphological and climate factors within the catchment area. Analysis of spectral signatures from various kettle holes showed that received spectra can be grouped in three types, i.e., Submerged vegetation, Phytoplankton dominated, and Mixed type. Application of the derivative analysis approach produces stable correlations with chlorophyll concentrations with all types of kettle holes, despite high noise influence on the surface reflectance caused by windy conditions during measurements. For example, in a typical small lake, K4 had its moderately turbid water, or for the shallow kettle hole K7, with its sandy bottom (Phytoplankton dominated type), the application of the derivative analysis approach is the best methodology. Derivative spectra of 2007 and biomass data perform the best correlation using the Peak Magnitude algorithm. For the season of 2008, the linear regression analyses between the derivative spectra and total chlorophyll (TCHL) produces a high determination coefficient using the Peak Magnitude algorithm. Correlation for chlorophyll-a (CHL) $\left(R^{2}=0.83\right)$ is slightly lower than TCHL $\left(R^{2}=0.84\right)$. Finally, the best cross-seasonal (2007-08) correlation uses derivative spectra and the Peak Magnitude algorithm $\left(R^{2}=0.84\right)$, despite high noise influences.

The method based on the reflectance values at a specific wavelength is the best applicable for high-algae-dominated ponds (Submerged vegetation type), such as K1 and K2 kettle holes. For example, linear regression between CHL and the Peak Magnitude algorithm gives consistent correlation for high algae content in kettle holes. At low algae content, Peak Magnitude Above a Baseline algorithm gives the best results, for instance, with kettle hole K7. However, the application of derivative analysis for this type of reflection also produces stable correlations.

Extraction of seasonal and, especially, cross-seasonal correlations for Mixed type of spectral signatures is a difficult task due to the high difference in the reflectance shapes. The available nutrients in kettle holes will either cause intensive algae growth (Submerged vegetation type) or cyanobacteria (Phytoplankton type), which will then benefit from the nutrient input and the lake becomes turbid with a dark green color [37]. Coefficients of linear determinations between volume reflectance and biomass concentrations produced low values for the season of 2008 and, consequently, for cross-seasonal combination (Mixed type). Only the season of 2007 has stable and high correlation near a chlorophyll absorption range of $680-690 \mathrm{~nm}$. Similar to volume reflectance correlations between TCHL and 
derivative spectra, it produces consistency only for $2007\left(R^{2}=0.94\right)$. Although the correlations with derivative spectra are better than with volume reflectance, the cross-seasonal linear regression coefficients are still very low $\left(0.1 \leq R^{2} \leq 0.3\right)$. Therefore, in the time of remote sensing image acquisition, kettle holes are dominated either by algae or phytoplankton [38]. Thus, the semiempirical algorithms have to be applied accordingly.

The accuracy assessment of the best cross-seasonal algorithms reveals that application of CHL as a proxy for the chlorophyll concentration produces good and stable results (Table 3 ). In almost all of the kettle holes, the cross-seasonal correlations with the CHL parameter have higher values than with TCHL. Field data analysis (Table 2) shows that the spectral signatures of the water bodies are kettle holes type specific and depend on the agricultural activity and respective nutrient status. The correlation between the spectral signals and the chlorophyll concentration is stable over one season as long as the type of kettle hole does not change.

Received results are important for water quality studies of kettle holes by means of airborne and satellite remote sensing. Unlike field spectrometers, the airborne and satellite remote sensors do not have such high spectral resolution. Therefore, integration of field spectrometry data for interpretation of the remote sensing images is an essential component in the classification of small shallow water bodies. Future research in the field of spectrometry can be focused on subsurface measurement and influence of fluorescence on the water leaving signal [5,39]. Precise understanding of the light attenuation under shallow waters can lead to detail interpretation of upwelling radiance.

\section{Acknowledgment}

This research was partially funded by German Academic Exchange Service (DAAD-scholarship № A/06/09937).

\section{References}

1. Merbach, W.; Kalettka, T.; Rudat, C.; Augustin, J. Trace Gas Emissions from Riparian Areas of Small Eutrophic Inland Waters in Northeast-Germany. In Wetlands in Central Europe; Broll, G., Merbach, W., Pfeiffer, E.-M., Eds.; Springer Berlin Heidelberg: New York, NY, USA, 2002; pp. 235-244.

2. Kalettka, T.; Berger, M.; Pfeffer, H.; Rudat, C. Integrated Conservation and Management of Kettle Holes in Young Moraine Agricultural Landscapes of Northeast Germany. In Proceedings of 21st European Regional Conference of the International Commission on Irrigation and Drainage, Frankfurt (Oder), Germany and Slubice, Poland, 15-19 May 2005; pp. 1-4.

3. Igamberdiev, R.M.; Lennartz, B.; Grenzdoerffer, G.; Bill, R.; Schubert, H. Analysis of spectral signatures of small water bodies (kettle holes) in the agricultural young moraine landscape of North-Eastern Germany. Int. J. Remote Sens. 2010, 31, 5495-5511.

4. Vohland, M.; Bossung, C.; Frund, H.C. A spectroscopic approach to assess trace-heavy metal contents in contaminated flood plain soils via spectrally active soil components. J. Plant Nutr. Soil Sc. 2009, 172, 201-209. 
5. Bhatti, A.M.; Rundquist, D.; Schalles, J.; Ramirez, L.; Nasu, S. A comparison between above-water surface and subsurface spectral reflectances collected over inland waters. Geocarto Int. 2009, 24, 133-141.

6. Jensen, J.R. Remote Sensing of the Environment: An Earth Resource Perspective, 2nd ed.; Prentice Hall: Upper Saddle River, NJ, USA, 2006; p. 592.

7. Wiangwang, N. Hyperspectral Data Modelling for Water Quality Studies in Michigan's Inland Lakes. Ph.D. Thesis, Michigan State University, East Lansing, MI, USA, 2006.

8. Salama, M.S.; Dekker, A.; Su, Z.; Mannaerts, C.M.; Verhoef, W. Deriving inherent optical properties and associated inversion-uncertainties in the Dutch Lakes. Hydrol. Earth Syst. Sci. 2009, 13, 1113-1121.

9. Matthews, M.W.; Bernard, S.; Winter, K. Remote sensing of cyanobacteria-dominant algal blooms and water quality parameters in Zeekoevlei, a small hypertrophic lake, using MERIS. Remote Sens. Environ. 2010, 114, 2070-2087.

10. Gomez, J.A.D.; Alonso, C.A.; Garcia, A.A. Remote sensing as a tool for monitoring water quality parameters for Mediterranean Lakes of European Union water framework directive (WFD) and as a system of surveillance of cyanobacterial harmful algae blooms (SCyanoHABs). Environ. Monit. Assess. 2011, 181, 317-334.

11. Lee, B.S.; McGwire, K.C.; Fritsen, C.H. Identification and quantification of aquatic vegetation with hyperspectral remote sensing in western Nevada rivers, USA. Int. J. Remote Sens. 2011, 32, 9093-9117.

12. Dekker, A.G. Detection of Optical Water Quality Parameters for Eutrophic Waters by High Resolution Remote Sensing. Ph.D. Thesis, Vrije Univecsiteit, Amsterdam, The Netherlands, 1993.

13. Gege, P.; Albert, A. A Tool for inverse Modelling of Spectral Measurements in Deep and Shallow Water. In Remote Sensing of Aquatic Coastal Ecosystems Processes: Science and Management Applications; Richardson, L.L., LeDrew, E.F., Eds.; Springer: Dordrecht, The Netherlands, 2006; pp. 81-109.

14. Bukata, R.P.; Jerome, J.H.; Kondratiev, K.Y.; Pozdnyakov, D.V. Optical Properties and Remote Sensing of Inland and Coastal Waters; CRC Press: New York, NY, USA, 1995; p. 362.

15. Liu, Y.S.; Islam, M.A.; Gao, J. Quantification of shallow water quality parameters by means of remote sensing. Prog. Phys. Geog. 2003, 27, 24-43.

16. Kneubuehler, M.; Gemperli, C.; Schlapfer, D.; Zah, R.; Itten, K. Determination of Water Quality Parameters in Indian Ponds Using Remote Sensing Methods. In Proceedings of EARSeL 4th Workshop on Imaging Spectroscopy, Warsaw, Poland, 27-29 April 2005; pp. 301-315.

17. Kalettka, T.; Rudat, C. Hydrogeomorphic types of glacially created kettle holes in North-East Germany. Limnologica 2006, 36, 54-64.

18. Porra, R.J.; Thompson, W.A.; Kriedemann, P.E. Determination of accurate extinction coefficients and simultaneous-equations for assaying chlorophyll-A and chlorophyll-B extracted with 4 different solvents-Verification of the concentration of chlorophyll standards by atomic-absorption spectroscopy. Biochim. Biophys. Acta 1989, 975, 384-394.

19. Lee, Z.-P. Remote Sensing of Inherent Optical Properties: Fundamentals, Tests of Algorithms, and Applications; The International Ocean-Colour Coordinating Group: Dartmouth, NS, Canada, 2006. 
20. Igamberdiev, R.M.; Lennartz, B. Spectral Response from Various Types of Kettle Holes: Analysis and Application of Remote Sensing Techniques for Chlorophyll Estimation. In Proceedings of 4th EPCN (European Pond Conservation Network) Conference, Berlin, Germany, 1-4 June 2010.

21. Gitelson, A.A. Nature of the peak near 700-nm on the radiance spectra and its application for remote estimation of phytoplankton pigments in inland waters. Proc. SPIE. 1993, 170, 170-179.

22. Doxaran, D.; Froidefond, J.M.; Castaing, P. A reflectance band ratio used to estimate suspended matter concentrations in sediment-dominated coastal waters. Int. J. Remote Sens. 2002, 23, 5079-5085.

23. Gitelson, A.; Yacobi, Y.; Rundquist, D.C.; Stark, R.; Han, L.; Etzion, D. Remote Estimation of Chlorophyll Concen-Tration in Productive Waters: Principals, Algorithm Development and Validation. In Proceedings of NWQMC National Conference, Austin, TX, USA, 25-27 April 2000; pp. 149-160.

24. Han, L.H. Spectral reflectance with varying suspended sediment concentrations in clear and algae-laden waters. Photogramm. Eng. Remote Sensing 1997, 63, 701-705.

25. Thiemann, S.; Kaufmann, H. Lake water quality monitoring using hyperspectral airborne data-A semiempirical multisensor and multitemporal approach for the Mecklenburg Lake District, Germany. Remote Sens. Environ. 2002, 81, 228-237.

26. Han, L.H. Estimating chlorophyll-a concentration using first-derivative spectra in coastal water. Int. J. Remote Sens. 2005, 26, 5235-5244.

27. Dekker, A.G.; Malthus, T.J.; Hoogenboom, H.J. The Remote Sensing of Inland Water Quality. In Advances in Environmental Remote Sensing, 1st ed.; Danson, F.M., Plummer, S.E., Eds.; John Wiley and Sons: London, UK, 1995; pp. 123-142.

28. Thiemann, S.; Kaufmann, H. Determination of chlorophyll content and trophic state of lakes using field spectrometer and IRS-1C satellite data in the Mecklenburg lake district, Germany. Remote Sens. Environ. 2000, 73, 227-235.

29. Scheffer, M. Ecology of Shallow Lakes; Springer: Berlin, Germany, 1998; p. 384.

30. Gitelson, A. The peak near $700 \mathrm{~nm}$ on radiance spectra of algae and water: Relationships of its magnitude and position with chlorophyll concentration. Int. J. Remote Sens. 1992, 13, 3367-3373.

31. Jiao, H.B.; Zha, Y.; Gao, J.; Li, Y.M.; Wei, Y.C.; Huang, J.Z. Estimation of chlorophyll-a concentration in Lake Tai, China using in situ hyperspectral data. Int. J. Remote Sens. 2006, 27, 4267-4276.

32. Murphy, R.J.; Underwood, A.J.; Tolhurst, T.J.; Chapman, M.G. Field-based remote-sensing for experimental intertidal ecology: Case studies using hyperspatial and hyperspectral data for New South Wales (Australia). Remote Sens. Environ. 2008, 112, 3353-3365.

33. Wang, J.J.; Lu, X.X.; Liew, S.C.; Zhou, Y. Remote sensing of suspended sediment concentrations of large rivers using multi-temporal MODIS images: an example in the Middle and Lower Yangtze River, China. Int. J. Remote Sens. 2010, 31, 1103-1111.

34. Han, L.H.; Rundquist, D.C. Comparison of NIR/RED ratio and first derivative of reflectance in estimating algal-chlorophyll concentration: A case study in a turbid reservoir. Remote Sens. Environ. 1997, 62, 253-261. 
35. Tsai, F.; Philpot, W. Derivative analysis of hyperspectral data. Remote Sens. Environ. 1998, 66, $41-51$.

36. Ma, R.; Tang, J.; Dai, J.; Zhang, Y.; Song, Q. Absorption and scattering properties of water body in Taihu Lake, China: Absorption. Int. J. Remote Sens. 2006, 27, 4277-4304.

37. Scheffer, M.; van Nes, E.H. Shallow lakes theory revisited: Various alternative regimes driven by climate, nutrients, depth and lake size. Hydrobiologia 2007, 584, 455-466.

38. Igamberdiev, R.M.; Grenzdoerffer, G.; Bill, R.; Schubert, H.; Bachmann, M.; Lennartz, B. Determination of chlorophyll content of small water bodies (kettle holes) using hyperspectral airborne data. Int. J. Appl. Earth Obs. Geoinf. 2011, 13, 912-921.

39. Gilerson, A.A.; Gitelson, A.A.; Zhou, J.; Gurlin, D.; Moses, W.; Ioannou, I.; Ahmed, S.A. Algorithms for remote estimation of chlorophyll-a in coastal and inland waters using red and near infrared bands. Opt. Express 2010, 18, 24109-24125.

(C) 2012 by the authors; licensee MDPI, Basel, Switzerland. This article is an open access article distributed under the terms and conditions of the Creative Commons Attribution license (http://creativecommons.org/licenses/by/3.0/). 